\title{
¿Es posible una televisión económica en España?
}

Elvira Calvo

Facultad de CC de la Información. Universidad Complutense

http://dx.doi.org/10.12795/AdMIRA.2011.01.04

\section{Resumen}

En España, la popularización del sector financiero en la década de 1980 trajo consigo una proliferación de publicaciones especializadas en información económica. En 1994 aparece Radio Intereconomía que actualmente se ha convertido en un referente histórico. La especialización llegó a la televisión gracias a los cableoperadores y las plataformas digitales. Durante poco mas de una década (1997-2009), han convivido dos modelos de televisión económica en España: Bloomberg TV e Intereconomía TV. Con diferentes planteamientos empresariales, ambas lograron hacerse un hueco en el mercado audiovisual. La primera cerró su sede española en 2009 como consecuencia de las graves consecuencias de la gran crisis financiera mundial que aún padecemos. La segunda ha sufrido diferentes avatares hasta llegar al 2011 convertida en una televisión generalista. Sin embargo, a los seguidores y consumidores de información económica, no les ha dejado huérfanos: Intereconomía Business emite desde hace un año para cubrir las expectativas de esta audiencia especializada.

\section{Palabras clave}

Información económica, medios especializados, audiovisual, televisión, Intereconomía $\mathrm{TV}$, Intereconomá Business

\begin{abstract}
In Spain, the popularization of the financial sector in the decade of 1980 brought a proliferation of publications specialized in economic information. In 1994 appears Intereconomia Radio that nowadays it's a historical model. The specialization came to the television thanks to the cableoperators and the digital platforms. During few more decade (1997-2009), have coexisted two models of economic television in Spain: Bloomberg TV and Intereconomía TV. With different managerial expositions, both they managed a hollow to be done on the audio-visual market. The first one closed his Spanish headquarters in 2009 as consequence of the serious consequences of the great financial world crisis that still we suffer. The second one has suffered different vicissitudes up to coming 2011 turned into a general television. Nevertheless, the followers and consumers of economic information, have not been left by it orphans: Intereconomy Business broadcasts for one year to cover the expectations of this specialized audience.
\end{abstract}

\section{Keywords}

Economic Information, specialized medias, audiovisual, television, Intereconoma TV, Intereconomia Business 


\section{Introducción}

El periodismo económico constituye posiblemente la plasmación más clara de la continua tendencia hacia la especialización que ha venido desarrollando la información en España. La co-existencia de varios diarios económicos, la proliferación de semanarios financieros, y la buena acogida de Intereconomía Radio parecían haber abonado el terreno para la existencia en nuestro país de una, o dos, televisiones netamente económicas, Bloomberg TV e Intereconomía TV. Realmente resulta sugestivo abordar el análisis de estos casos, en especial el segundo por su condición de "netamente española", ya que aúnan lo que parece ser la información más complicada, la economía, y el canal más difícil, la televisión. Resulta paradójico calificar a la televisión como el canal más difícil. La televisión es el medio de comunicación de masas por excelencia. Es audiovisual. Imagen y sonido combinados y sincronizados de forma interdependiente. La coordinación simultánea de imágenes visuales, acústicas y verbales es la base del lenguaje audiovisual, que nos permite comprender la representación de la realidad. Informa, entretiene y forma. Resulta, realmente, muy difícil hablar 24 horas de economía en televisión. De cómo hacerlo trata el presente trabajo.

La coexistencia de dos canales temáticos financieros en España rompió la idea de que la información económica no tenía cabida en un medio audiovisual. Tradicionalmente, los profesionales consideraban que la televisión era un medio poco apropiado para transmitir este tipo de noticias, en primer lugar, por las propias limitaciones estructurales y de lenguaje, pero también por la poca aceptación que tenía entre los telespectadores. En todas las mediciones de audiencia de un diario televisado, el índice caía en los minutos dedicados a economía, y sin embargo subían espectacularmente cuando se iniciaban los deportes. Cabe preguntarse si era una pescadilla que se muerde la cola: a la gente no le interesaba la economía porque no hablaban de ella en televisión o la televisión no hablaba de economía porque consideraba que a la gente no le interesaba. Lo cierto es que la información sobre finanzas y empresas no interesó en España hasta casi finales de la década de los años 80 .

La información económica puede ser muy complicada por el lenguaje que utiliza, la escasa cultura económica de la audiencia general y por su difícil tratamiento en un medio como la televisión. Sin embargo, hoy, ningún canal generalista puede permitirse el lujo de excluir las noticias económicas más importantes. 
La información financiera se puso en auge en nuestro país en los 90, no por la euforia económica del momento, sino como consecuencia del propio desarrollo de los medios y la creciente demanda informativa de la audiencia. Hoy, en medio de una crisis finaciera mundial, es frecuente que los informativos abran con noticias económicas. Sin embargo, esta crisis también ha servido para poner a los medios en su lugar, incluso lo que hablan de economía. Bloomberg TV tuvo que cerrar su sede español en 2009. Intereconomía TV ha virado hacia una televisión generalista. ¿No hay hueco para una televisión económica en España? Intereconomía Business cubre desde hace un año, el hueco que dejaron las dos citadas anteriormente.

\section{Metodología}

La metodología seguida para la elaboración de este artículo se basa en el seguimiento durante años de los canales temáticos especializados en economía durante los últimos años. Al centrarse básicamente en la trayectoria del canal español, ha sido posible la realización de entrevistas personales con los directivos de los canales estudiados. Por último, también ha sido fundamental el seguimiento del tema en los medios de comunicación.

Las principales fuentes de información a las que se ha recurrido para la elaboración de esta tesis han sido, en primer lugar, el visionado de los canales objeto de estudio, Intereconomía TV e Intereconomía Business, y en segundo lugar, las entrevistas personales y en profundidad realizadas a los directores y redactores jefes de los canales. Asimismo, ha sido fundamental la consulta de bibliografía y la revisión de textos de autores especializados y publicaciones de la Asociación de Periodistas de Información Económica (APIE).

Por último, Internet ha sido, sin duda, una fuente inagotable, constante y actualizada. Mucho se ha escrito sobre información económica como especialización periodística, pero muy poco sobre su proyección en el medio televisión. A destacar, la nula bibliografía sobre televisiones españolas especializadas en economía, cuyo análisis conforma mi mayor aportación.

\section{La información económica audiovisual en España}

El tirón de la prensa económica en la década de los 90 ayudó al aumento de la 
información económica en los medios audiovisuales españoles, más en radio que en televisión. Las emisoras, como las televisiones, mejoraron sus secciones de economía y además crearon programas específicos sobre el tema. Ante la demanda de profesionales expertos, muchos redactores iniciaron así su especialización, un reto que exigía, además de enfrentarse al difícil lenguaje económico, solventar los problemas intrínsecos del propio medio. El concepto se amplía con el desarrollo de las nuevas tecnologías con la aparición de portales financieros.

Como señalaba Balsebre (1994: 57), la radio, más ágil que la televisión, ha creado espacios de debate y opinión, en forma de tertulias, y otros de participación del oyente, al estilo de los consultorios . Desde mediados de los años 80, la información económica se ha abierto camino en la radio y los informativos radiofónicos ya cuentan con una importante sección de economía, una materia que era considera como la convidada de piedra, la que se reservaba para el final y la que sirvió para dar lustre a los servicios informativos de RNE. A partir de este ejemplo, todas las emisoras mejoraron su sección de economía y crearon también programas específicos. Las radios comerciales aprovecharon el tirón. Las conexiones con la bolsa se fueron ampliando y en ocasiones llegaron a convertirse en pequeños coloquios en los que se utilizaba un lenguaje muy accesible para todo tipo de público. Fueron, y son, auténticos espacios económicos que, generalmente, están patrocinados por una sociedad de valores y bolsa u otra entidad financiera. Actualmente, algunos de esos programas subsisten aunque dependen de las posibilidades de financiación y el patrocinio, generalmente de entidades financieras (Calvo, 2009: 99-109).

En cuanto a la información económica en televisión hay que remontarse a 1974 -cuando nace la Asociación de Periodistas de Información Económica (APIE)-, para vislumbrar un flujo de información económica que en el medio televisivo empieza a ser importante dos años después, con la crisis del petróleo y las reivindicaciones sindicales (Piedrahita, 1998: 72). Con la consolidación de la democracia, la economía pasa a un primer plano. Nacen los diarios económicos y la expectación por la información financiera. Como en la radio, también la información económica comienza a ganar presencia en televisión durante los años 70 y 80 , siempre un poco más rezagada. Se consolida la sección en TVE y, en los 90, con la aparición de las televisiones privadas, se acortan distancias. Aparecen los primeros programas especializados en la materia pero con escasos resultados, la televisión era un medio para entretener. En general, eran programas de públicos bastante 
restringidos y que se emitían en horarios de audiencias específicas (Cebrián, 1998: 97). Como indica Cebrián, estos programas aparecían con tres niveles de divulgación: para el gran público, para determinados telespectadores preocupados por aspectos específicos de la economúa y para expertos.

Los programas de información económica abarcan un espectro amplio de temas sobre economía en general, mundo empresarial, mundo de los negocios; se seleccionan aquellos que puedan ser de mayor interés para la audiencia y de clara exposición por televisión. Temas como el paro, la inflación, subida de impuestos, subida de precios, tendencias empresariales referidas a diversos sectores de producción y servicio son de frecuente presencia en los programas centrados en economía. Son programas de duración media, de aproximadamente 30 minutos, semanales o diarios (salvo los fines de semana).

Los programas pioneros en economía fueron en la monopolizada TVE que emitió Cuarto y mitad (1976-77), Mas-Menos (1977), Tribuna de la economía (1978-81); El canto de un duro (1978 en el segundo canal), y La Bolsa y la vida. Coincidiendo con estos programas, TVE consolida su sección de economía de la que han surgido periodistas como Javier Gilsanz o Carmen Sastre. Otros programas fueron Campo y mar, Agrosfera (1997), La bolsa y el dinero (2000-01), Impulso, dirigido por Luis Aparicio y espacios patrocinados como Emprendedores y España innova, de dos minutos de duración que se emitían por La 2, un día por semana, y a las 20:55 horas.

De las privadas, destaca Antena 3 con su programa Noticias de economía (1990-92); en Canal + iniciaron un pequeño boletín de cuatro minutos en horario nocturno, o Plusvalía (1995-97) que acaba cuando el canal pasa a ser en abierto y convertirse en Cuatro; y en Tele 5, Noticias y Negocios (1995-96), o más tarde, Mi Cartera, que se emitía los sábados a la 1 de la madrugada. Estos programas, a pesar de su escaso éxito, deberían ser considerados como los pioneros de las televisiones especializadas en economía. Pocos sobrevivieron o derivaron en microespacios como Avances o Mi Cartera que continúa actualmente aunque sin horarios fijos (Calvo, 2009: 109-115).

La extinta $\mathrm{CNN}+$ española, del grupo Prisa hasta su reciente venta a Tele5 en diciembre de 2010, contaba en su parrilla con varios programas específicos financieros, como Economía 23, dirigido por Alonso Trenado y que se emitía todos los días de 23:30 a 00:00 h. También en la TDT encontramos dos canales con programas especializados en 
economía: Economía para todos en Libertad Digital, dirigido y presentado por la periodista Carmen Tomás los miércoles a las 23:15 con varias redifusiones a lo largo de la semana; y Veo Expansión en Veo TV, que emitía todos los días, de 00:00 a 00:25 h., un programa formativo más que informativo ya que se autosubtitula "El master en economía más popular, informal y abierto del universo". Telemadrid fue el último canal en incorporar, a partir del 4 de febrero de 2004, un nuevo programa sobre economía, Gabinete de crisis, presentado por Ana Samboal, los martes a las 21.30 horas.

Salvo estos casos excepcionales, pocas televisiones generalistas se han querido enfrentar al reto de realizar un programa específico de economía. Con la televsión analógica, algunas televisiones locales compraban espacios a otra para completar su programación. Fue el caso de Canal 7 que, mediante un acuerdo con Bloomberg TV, en tres ocasiones diarias, emitía la programación española del canal financiero. Canal 7 lo utilizaba como informativo pero, claro está, tenía un altísimo componente económico, lo cual no se correspondía con el perfil generalista de su público.

Estos programas son testigos indudables del intento, por parte de las televisiones generalistas, de tratar el especialización, aunque el esfuerzo nunca se vió recompensado. Sólo con la aparición de las plataformas digitales y los primeros canales temáticos, pudimos ver televisiones específicas de economía. El auge del periodismo económico en televisión se alcanza, por tanto, gracias al aumento de la programación y de los contenidos que ofrece la televisión de pago a través de múltiples plataformas: Digital Plus, cable (ONO o Imagenio/Movistar de Telefónica).

Hablamos de la década de los 90. Bloomberg TV se instala en España en 1997. Pocos meses después, y con una estrategia similar, desembarca en España el grupo mexicano Televisa, liderado por el magnate de medios Emilio Azcárraga, que pone en marcha el segundo canal financiero para los españoles. Conexión Financiera, un proyecto que se trunca al año de nacer tras la muerte del propio Azcárraga. El canal fue adquirido por el grupo Recoletos que puso en marcha Expansión TV que, tras siete años de emisión, fue vendido al grupo Intereconomía.

Este artículo se centra en las televisiones especializadas en economía de España, y mas concretamente, en una de ellas, mas conocida como Intereconomía TV. Sus orígenes, su trayectoria y su evolución, forman el corpus de este texto que trata de reflejar las 
andanzas y dificultades de un canal de televisión económico en España.

\section{4.- Andanzas y avatares de una televisión económica}

El auge del periodismo económico comenzó en España hacia 1985, año a partir del cual, como ya se ha apuntado, las secciones de economía en radio y televisión empezaron a ocupar un lugar destacado en las redacciones, coincidiendo con la llegada de los primeros diarios especializados en la materia. La aparición en 1994 de la especializada Radio Intereconomía supuso una reserva para el sector, sin embargo, la emisora se instalaba en el mercado avalada por las numerosas publicaciones especializadas en economía y finanzas que confirmaban que, en España, los asuntos económicos interesaban, y mucho.

Lo que no estaba tan claro era si entre las audiencias había un hueco para canales similares en televisión. Los profesionales y los empresarios de medios de comunicación conocían, sin duda, la existencia de Bloomberg TV y de Reuters TV (ya desaparecida), pero eran canales, o herramientas, que se integraban en algo mucho más complejo que la puesta en marcha de una televisión. Por otro lado, la legislación española y la adjudicación de licencias era un tema demasiado complejo para intentar un canal temático económico.

La llegada de los cableoperadores y las plataformas digitales en los 90 cambió ese panorama. Nacía la televisión de pago y, con ella, el aumento de las ofertas de contenidos, entre ellos, los económicos. Boomberg TV, que dirigía la división europea desde Londres, se instalaba en España en 1997 como una herramienta del todopoderoso grupo financiero Bloomberg LP. Su trayectoria fue paralela a la evolución del grupo multinacional que, tras la crisis financiera iniciada en 2008, cerró todas sus delegaciones extranjeras. Actualmente, llega a los hogares españoles a través de la plataforma digital y en inglés.

Frente a Bloomberg TV, nos encontramos otro canal, que definiremos como español, y cuya interesante trayectoria se desarrolla a continuación, en un intento de evidenciar los problemas a los que se enfrente un canal especializado en España y poder obtener conclusiones sobre la posibilidad de su supervivencia. A modo de resumen, digamos que este canal español se inició de la mano del grupo mexicano Televisa, luego pasó a ser propiedad del grupo Recoletos y, finalmente, fue adquirido por el grupo Intereconomía. En ocho años, el canal ha pasado por tres propietarios pero siempre con un único 
objetivo: hacer 24 horas de televisión económica.

\subsection{Conexión Financiera (1997-1998)}

Cuando apenas Bloomberg TV había iniciado sus emisiones en España, en 1997 aparece un segundo canal financiero que pone en marcha el grupo mexicano Televisa, perteneciente a la familia Azcárraga. Televisa contaba con un canal económico, Conexión Financiera que, desde su sede central en México D.F., transmitía vía satélite a diversos países de influencia latinoamericana. Después de abrir sucursal en Nueva York, Televisa entró en el mercado español, de la mano del periodista Julio Fernández. Como todos los inicios, los suyos también fueron duros, y especialmente porque coincidieron con la muerte del fundador de Televisa, Emilio Azcárraga Vidaurreta. Problemas con sus herederos y cambios de estrategias, hicieron que el proyecto tuviera muy poca fortuna y terminara fracasando al año y medio de su nacimiento.

\subsection{Expansión TV (1998-2005)}

La herencia de ese equipo en España pasó a manos del grupo Recoletos que, a través de un acuerdo, se quedó con parte del equipo técnico y humano, dirigido en esta ocasión por el periodista Salvador Arancibia, cuyas valoraciones forman parte de las conclusiones de este trabajo. Líderes en la prensa económica gracias al diario Expansión, Recoletos había decidido probar suerte en los medios audiovisuales. Paralelamente a la compra de la televisión, obtuvo una licencia de radiodifusión para una emisora que llevaría el nombre de la cabecera: Radio Expansión. Con licencia para emitir, con equipos y recursos humanos, el proyecto nunca llegó a ser una realidad. La aventura televisiva, en cambio, sí salió adelante aunque sólo sobrevivió siete años (1998-2005).

Tras el acuerdo con Televisa, el canal fue rebautizado como Expansión Financiera y se podía ver a través de Vía Digital. Una tímida programación se completaba, al principio, con el canal mexicano, hasta que el acuerdo terminó y Recoletos se quedó con el cien por cien del canal. Esto ocurría en marzo de 1998, justo un año después de que Bloomberg empezara a emitir una televisión de 24 horas noticias económicas. No cabe duda que fue un referente, aunque les diferenciaran mentalidades completamente antagónicas. El control de Recoletos se dejó sentir desde el principio en la programación. Los contenidos seguían siendo económicos pero mucho más centrados en el mercado español, en detrimento del americano que no interesaba tanto, según la nueva filosofía empresarial. "Lo importante es qué pasa en España y sobre todo en la bolsa española con leves pinceladas de lo que pasa en el resto del mundo sin ejercer ningún magisterio en esos 
temas", explicaba el entonces director de informativos Javier Marquina.

Pero el modelo de negocio que se había creado para Expansión TV entró en crisis en 2002, a los cuatro años de su nacimiento. La causa inmediata era la fusión de las dos plataformas digitales. El papel de los suministradores de contenidos, como Expansión TV, pasó de tener un papel importante a un papel subordinado. Una de las dos plataformas, Digital +, había asumido el coste de subir la señal de Expansión TV al satélite. Con la fusión de ambas, ese acuerdo se rompe. Por un lado, se introduce un gasto en la cuenta de explotación de Expansión TV muy elevado; y se produce en un momento en el que la publicidad en ese tipo de televisiones no acababa de crecer, a pesar de ser una de los canales temáticos que más publicidad tenía. No daba para compensar los incrementos de costes que se habían experimentado. Y no es que se diera sólo ese año, todo apuntaba a que el modelo de negocio no crecería compensatoriamente (Bloomberg TV se lo podía permitir porque no está concebido como un negocio sino como un producto de marketing de la agencia Bloomberg que lo asume si problemas).En cualquier caso, Expansión TV sentó las bases de un periodismo económico televisivo de calidad. Frente a la solidez de Bloomberg TV, no deja de sorprender la trayectoria y los intentos por sobrevivir del segundo canal económico que se implantaba en nuestro país, y el primero netamente español. El cuadro siguiente recoge esa evolución.

\subsection{Intereconomía TV}

A primeros de mayo de 2005, el grupo Recoletos toma la decisión de cerrar el canal que había puesto en marcha siete años antes, en 1998. En ese momento, el grupo Intereconomía se acerca y negocia su compra, comprometiéndose a mantener, al menos durante un año, la plantilla existente en ese momento.

Liderado por Radio Intereconomía que ya ha cumplido 17 años, el grupo Intereconomía se ha hecho fuerte en los últimos diez, debido en parte a su principal accionista y presidente, Julio Ariza. En la radio, la información económica y financiera ocupan un destacado primer plano que se combina con la información general (política, cultural, social...) y otros contenidos de entretenimiento. Con una audiencia de clase media-media alta, con alto poder adquisitivo, profesional liberal o empleado con cargo de influencia, Radio Intereconomía presta especial atención a la información de los mercados financieros de todo el mundo en tiempo real, así como a otros contenidos destinados a empresarios, directivos, profesionales autónomos, etc. Es habitual la participación en 
directo de empresarios, directivos, expertos el mundo académico y otros líderes de opinión. Es una de las radios españolas más valoradas: una encuesta realizada por Sigma 2 en 2007 revela que el 66\% de los encuestados considera que Radio Intereconomía tiene los mejores contenidos de Bolsa de la radio española. Su programación se divide en cuatro bloques: economía y empresa, Política y actualidad, Cultura y estilo de vida, y Música. El grupo cuenta con otras pequeñas emisoras, revistas y la extinta agencia Fax Press que cerró en 2009.

Su aventura televisiva se inicia con la compra de Expansión TV, que se produce el 27 de mayo de 2005. Cuatro días después, el 1 de junio, la televisión cambia de nombre, cambia la "mosca" y se transforma en una nueva televisión aunque con la misma plantilla y el mismo equipamiento. Pasa a emitirse por Digital Plus.

Las valoraciones de su primer director, Javier Horcajo, han sido importantes para la realización de esta trabajo. El grupo tenía potencialidades y sinergias que se vieron impulsadas por la TDT. Le avalaban los 15 años de experiencia de su hermana mayor, la radio. En ese tiempo han aprendido a hacer una radio divulgativa de lo económico, una radio económica, fiel a la información de los mercados en tiempo real cada 30 minutos, con un lenguaje asequible a la audiencia. De hecho, según Horcajo, el éxito de Intereconomía Radio no puede justificarse en base a que todos los oyentes que la escuchan, invierten en bolsa. El contacto con la audiencia les ha enseñado que no todos tienen dinero, ni interés por invertir en bolsa, pero les gusta su estilo. ¿Por qué? Porque es un estilo valiente y atrevido pero muy respetuoso con las personas, un estilo que tiene poco que ver con los modelos radiofónicos convencionales. Ese modo de hacer se ha consolidado con una fase de éxito en audiencias y con una solvencia económica saludable. El grupo Intereconomía no es de los más ricos de España, de hecho se proclama modesto pero orgulloso de saber lo que hace. El reto, al adquirir la televisión, era saber si serían capaces de trasladar el éxito radiofónico a la pantalla. Estratégicamente, quieren situarse como líderes de la información económica audiovisual y creían que, en el hueco dejado por Expansión TV, tenían un nicho en el que jugar sus cartas. Esa es la razón por la que adquirieron la televisión de Recoletos.

Desde 2008, se ha convertido en proveedora de información nacional a nivel mundial, al ser corresponsal en España de CNBC, la televisión económica líder en el mercado norteamericano actualmente. Día tras día, con cinco conexiones informativas, en todos 
los rincones del mundo se escucha la voz de un redactor de Intereconomía que va desgranando el comportamiento de las empresas españolas en la bolsa y sus decisiones estratégicas más importantes.

En 2010, se autoconsideraba la primera televisión económica y financiera de España. Su posicionamiento es de liderazgo en la actualidad informativa para un público "que no tiene tiempo ni dinero que perder". A lo largo de los últimos años ha consolidado su posición con gran prestigio y valoración por parte del público que se compone en gran medida de personas con poder adquisitivo alto y medio-alto. Un público preocupado por la actualidad empresarial española e internacional.Intereconomía TV emite la señal producida en los estudios de Intereconomía, siendo el único canal español con producción $100 \%$ propia, que informa de los mercados financieros, nacionales e internacionales, las empresas, la economía global y las oportunidades de inversión y de negocio.

Desde el 1 de marzo de 2008, fecha de inicio de las emisiones en TDT nacional en abierto, la programación se amplió con contenidos generalistas, pero sin abandonar la especialización. Su programación se basaba en conexiones en directo con las Bolsas más importantes del mundo, comentarios de los analistas más prestigiosos, y entrevistas con los protagonistas de la actividad económica española e internacional. La parrilla se completaba con espacios de información general y otros de diversas temáticas, siempre adaptados al estilo de vida de sus telespectadores. Además, era el corresponsal de la Bolsa y la economía españolas para la líder mundial de la información económica, la norteamericana CNBC. Cuando los mercados cerraban, Intereconomía TV apostaba por la programación generalista, de ocio y entretenimiento con programas como El gato al agua (que fue el primer programa interactivo de la TDT española), Los clones, Más se perdió en Cuba o España en la Memoria. El giro radical ha sido en 2010, tras el éxito de programas como "El gato al agua" cuya popularidad y apoyo por parte de un sector social concreto, les ha animado a convertirse en un canal generalista.

$\mathrm{Su}$ programación se basaba un modelo informativo mixto, similar a la CNBC: informacion económica y financiera mientras los mercados estuvieran abiertos. Después, buscaban entretenimiento y lo social (es el modelo que sigue la CNBC, mas orientada a los deportes durante el fin de semana). El ámbito internacional era cubierto por la CNBC estadounidense, de la que el canal español era corresponsal. Desde 2006, incorporaron noticias deportivas en sus informativos. $\mathrm{Su}$ deseo fue popularizar la información 
económica, no en el sentido de que sea masiva pero sí extenderla a segmentos más amplios de la sociedad.

A raíz de la obtención de la licencia digital nacional, Intereconomía TV comenzó a remodelar su imagen corporativa y su programación para afrontar el reto de la TDT nacional. Desde octubre de 2009, y paulatinamente, se ha sustituído programación, apostando por la política, el humor y la sociedad, y alejándose de su nacimiento como televisión económica. Actualmente, ya es una televisión generalista, con importante apoyo en los debates políticos. De los nuevos canales digitales terrestres, sigue siendo la más exitosa con un porcentaje de seguimiento del $1,1 \%$, por encima Veo $7(0,8 \%)$, del Canal 24 horas $(0,7 \%)$, del ya desaparecido $\mathrm{CNN}+(0,6 \%) 0,1 \%)$.

\subsection{Intereconomía Business}

Pero el grupo no ha dejado huérfanos a sus fieles seguidores de información económica y bursátil especializada. El 11 de enero de 2010, unos meses antes del apagón analógico, se puso en marcha Intereconomía Business, un canal que mantiene la esencia del grupo y que mantiene grandes sinergias con la madre radio. El proyecto nace con ambición, pues aunque a través de la TDT sólo se puede ver en Madrid, algunos operadores lo han incluído en su oferta, como Imagenio/Movistar y ONO y, además, parece que el grupo está sondeando la posibilidad de llegar a otros países de habla hispana.

En una entrevista personal con Javier Ablitas, subdirector del nuevo canal, éste nos explica que la conversión de Intereconomía TV hacia una televisión generalista hizo que la información económica perdiera perso, pero el grupo entendía que existe un nicho de mercado y un know-how que no hay que abandonar. Por eso, a finales de 2009 se apuesta por un proyecto de información de negocios que se asiente en la estructura ya consolidada de Intereconomía TV. La idea de fondo es la misma: información económica en tiempo real. La diferencia es que Intereconomía TV puso las bases del proyecto audiovisual del grupo, todo un reto $\mathrm{y}$, en su momento, una incógnita.. Ahora Intereconomía Business nace sobre un proyecto consolidado $\mathrm{y}$, por lo tanto, las exigencias y la responsabilidad son distintas.

Ambos canales comparten infraestructuras (departamento técnico y parte de la redacción y producción) y recursos (recursos humanos, administración, etc.) junto al resto de medios del grupo. Cuenta con cinco platós y una plantilla de 60 personas de manera 
directa. Emite durante 24 horas, en directo desde las 7.30 hasta las 22.00 horas, de lunes a viernes. El resto es programación, incluyendo los fines de semena, es en diferido. Una parte importante de la programación en directo se emite de manera simultanea con (Radio Intereconomía) y existen sinergias tanto con la web como con el diario La Gaceta.

Los programas que fueron emblemáticos en Intereconomía TV (Capital -apertura del mercado español, de 8 a 10 h.) - y Cierre de mercados -de 15 a 19 h.) tienen continuidad en el nuevo canal que presenta como novedad en su parrilla los magazines Magabusiness (de 12 a 13 h. y de 19 a 20 h.) y Business Connection (de 20 a 21 h.). Se mantienen los boletines informativos cada media hora y dos consultorios bursátiles (a las 9.30 y 18.30 h), un género que siempre ha contado con una buena respuesta por parte del público. No existen datos precisos sobre su audiencia y quizá sea demasiado pronto para hacer balance pero se puede afirmar que los programas heredados siguen siendo la referencia informativa del canal y que el objetivo a corto plazo es la consolidación del proyecto con la ampliación de la cobertura que ofrece la TDT a las principales capitales de provincia.

Ha cambiado el acuerdo con la CNBC, de la que Intereconomía TV era corresponsal en España, con varias conexiones diarias. Para mantener su independencia, el grupo ha optado por una estrecha relación con el canal estadounidense. Un periodista de Intereconomía Business hace una crónica diaria en directo a primera hora con la apertura del mercado español. Además se mantienen intercambios de material y producción. El último ejemplo fue la emisión en exclusiva en España por parte de Intereconomía Business de la entrevista que José Luis Rodríguez Zapatero concedió a CNBC durante su visita a Estados Unidos (23 de septiembre)

Según fuentes del grupo, el modelo del grupo funciona con "eficiencia, sinergias y costes controlados". De momento se han puesto los cimientos del proyecto. Ahora tiene que crecer para ser autosuficiente. El tiempo, y la trayectoria que ha seguido la información económica en televisión en España, parecen dar la razón al grupo: el canal sólo tiene sentido en un grupo como Intereconomía, con una cultura corporativa de colaboración y aquilatamiento de costes que ha conseguido que en los dos últimos años la plantilla se haya casi duplicado pese a la crisis.

\section{Conclusiones}

Una de las conclusiones mas interesantes podría ser la evidencia de lo difícil que resulta 
mantener un canal especializados en economía. El canal español, desde sus inicios, ha pasado por diferentes manos y todas tenían un proyecto a largo plazo que se ha visto impulsado por las nuevas tecnologías de la información y la comunicación pero truncado por problemas económicos.

Antes, debería aludirse a que como especialidad, la información económica sigue siendo una de las mas complejas y difíciles del periodismo. Prueba de ello son las dificultades a los que se han enfrentado algunos programas especializados en las televisiones generalistas y los propios problemas de subsistencia de los canales temáticos que, en su día, optaron por ofrecer una programación altamente especializada. El lenguaje técnico, la especialización que se requiere de los profesionales, los elevados costes de una televisión y la minoritaria audiencia, no justifican la existencia de una canal temático económico, salvo que pertenezca a un grupo consolidado en la especialización, como es el caso de Intereconomía.

Intereconomía Business es, a día de hoy, el único canal especializado en economía que emite en español. Su cobertura nacional a través de la TDT no es completa, aunque puede verse en todo el país a través de la plataforma digital y cableoperadoras. Apenas tiene un año de vida pero cuenta con una base sólida que heredó de Intereconomía TV.

El canal español de Bloomberg TV permaneció en antena durante 12 años, de 1997 a 2009, cuando el grupo multinacional cerró todas sus divisiones extranjeras ante la crisis financiera mundial. Hoy, en España, sólo puede verse en inglés y a través de la televisión de pago.

Sin embargo, la información especializada en economía aparece como una demanda de la audiencia y una necesidad evolutiva de los propios medios. Cada vez más, y siguiendo una tendencia universal, las audiencias se especializan y se definen por sectores. El hecho de que el español medio invierta sus ahorros en la Bolsa, implica una mayor demanda de información económica. Nace un nuevo tipo de audiencia, la interesada en la economía, la que quiere saber más y conocer todos sus entresijos. Desde los pequeños inversores hasta los profesionales de las finanzas, todos quieren, como telespectadores, que la información responda a sus necesidades. La profusión de diferentes plataformas de televisión (satélite, cable y TDT) ha sido un factor desencadenante para la existencia de canales temáticos y, dentro de estos, para los canales especializados en economía. 
Los canales analizados en este trabajo, -con un modus operandi similar y distintos puntos de vista empresarial-, han aprovechado su capacidad expresiva y lingüística para establecer una correcta comunicación en el ámbito de la información económica. La posibilidad de ofrecer gráficos, de poner caras a las noticias económicas y de ofrecer información de los mercados, tanto españoles como internacionales, en tiempo real ofrecen una clara ventaja competitiva frente a otros medios, supliendo así sus carencias estructurales. Se trata de un lenguaje propio que tiende a reducir las cifras y los datos utilizando sinónimos o comparaciones y ayudándose de los avances que hoy permite la infografía, todo ello sin perder el rigor que la materia requiere. Ese lenguaje propio es una peculiaridad de la información económica audiovisual.

Estos nuevos discursos televisivos de la información económica presentan, pues, algunas peculiaridades:

-Un lenguaje más técnico, caracterizado por ir de la información general a la específica, centrándose en analizar la economía desde un punto de vista profesional, donde la información generalista sólo sirve como referente. Un lenguaje que se complementa con tratamientos específicos que incluyen imágenes, gráficos y postproducción propios.

-Un lenguaje que sirve para informar, formar y entretener y captar audiencia.

-Por sus implicaciones políticas, empresariales y sociales, la información económica audiovisual recibe un tratamiento serio, riguroso y divulgativo a pesar del ostracismo que, en ocasiones, presentan las fuentes, el marketing y las relaciones públicas.

-La concepción de la pantalla es diferente a la tradicional. La sobreimpresión de datos o tickers que ofrecen información financiera en tiempo real es una característica fundamental.

-El seguimiento de los mercados bursátiles, nacionales e internacionales, es el pilar de la programación y su razón de ser, al informar en tiempo real de la evolución de los valores. De él se deriva el éxito de los consultorios bursátiles y la interactividad de la audiencia que participa pidiendo consejos y recomendaciones tras exponer sus preocupaciones inversionistas.

-Las audiencias definen el modo de hacer en estos canales temáticos: periodismo de intermediación, en el caso de Bloomberg $\mathrm{TV}$, frente al periodismo interpretativo que practica el análisis y la crítica, en el caso de los canales de Intereconomía. 
Apuntados los problemas a los que se enfrenta la información económica en un canal temático, es imprescindible añadir, de cara a futuros análisis, la importancia que están adquiriendo los portales financieros de Internet. Irrumpen con fuerza el periodista multimedia, las ediciones digitales y los nuevos medios que con costes inferiores, son más rentables. Quizá se pueda afirmar que, al menos en España, el desarrollo de la información económica ha tocado techo en cuanto a medios tradicionales (prensa, radio y televisión). Frente a esta visión catastrófica, Internet se ofrece como la vía más factible para asegurar y mantener la información económica ante un público fiel. Portales financieros, diarios económicos digitales y blogs de expertos empiezan a constituirse en la primera fuente de información económica para periodistas y particulares. ¿Hablamos de una nueva etapa de la información económica?.

\section{Referencias bibliográficas}

BALSEBRE, A. (1994). El lenguaje radiofónico. Madrid: Cátedra

CALVO, E. (2009) La información económica en televisión. Canales temáticos. UCM, 2009. Tesis doctoral. Disponible en http://eprints.ucm.es/11290/1/T31777.pdf

CEBRIÁN HERREROS, M. (1998) Información Televisiva. Mediaciones, contenidos, expresión y programación. Madrid: Síntesis

PIEDRAHITA, M. (1998) Periodismo impreso, audiovisual y electrónico del siglo XXI. Madrid: Universitas

\section{Webgrafía:}

Bloomberg TV: http://www.bloomberg.com/

Intereconomía TV: http://www.intereconomia.com/

Asociación de Periodistas de Información económica: http:/www.apie.es/ 